\title{
Do conceito de informação ao discurso sobre competência em Informação
}

\author{
From the concept of information to the discourse on information literacy
}

\begin{abstract}
Carlos Robson Souza da Silva
Mestre em Ciência da Informação pela Universidade Federal do Ceará - UFC, Brasil. Bibliotecário no Instituto Federal de Educação, Ciência e Tecnologia do Ceará - IFCE, campus Cedro, Brasil.

E-mail: crobsonss@gmail.com https://orcid.org/0000-0002-6489-3210
\end{abstract}

Jefferson Veras Nunes Doutor em Ciência da Informação pela Universidade Estadual Paulista Júlio de Mesquita Filho - UNESP, Brasil. Professor adjunto do Departamento de Ciências da Informação da Universidade Federal do Ceará - UFC, Brasil. https://orcid.org/0000-0003-4684-0489 E-mail: jefferson.veras@yahoo.com.br

Thiciane Mary Carvalho Teixeira Doutora em Ciência da Informação pela Universidade Estadual Paulista Júlio de Mesquita Filho - UNESP, Brasil. Professora adjunta da Universidade Estadual do Ceará - UECE, Brasil.

E-mail: thiciane.teixeira@uece.br https://orcid.org/0000-0003-1873-0047

\section{Resumo}

O presente artigo tem como objetivo relacionar as teorias da informação ao discurso de Competência em Informação. Trata-se de uma pesquisa do tipo exploratória, de abordagem qualitativa, que possui como instrumento de coleta de dados a pesquisa bibliográfica e documental. Aborda o conceito de informação e seus paradigmas e como esses paradigmas influenciaram o desenvolvimento da Ciência da Informação, sua conceituação e subáreas. Tem como resultados o fato de que a Competência em Informação esteve três distintas abordagens de acordo com os paradigmas da informação e uma abordagem custodial: 1 - custodial, ligada ao conceito de Educação de Usuários; 2 - física, que a compreendia sob o ponto de vista do acesso a documentos e dados; 3 - cognitiva, no qual se compreendia o papel da satisfação das necessidades de informação dos indivíduos; e 4 - social, que compreende o papel da Competência em Informação na formação social, ética e política dos indivíduos. Conclui que a Competência em Informação tem apresentado características distintas concomitantemente ao desenvolvimento das Teorias da Informação, enfatizando ora os aspectos físicos da informação, ora os cognitivos, ora os sociais.

Palavras-chave: Competência em Informação. Teoria da Informação. Ciência da Informação.

\begin{abstract}
This article has as objective to make a relation among information theories and the Information Literacy discourse. It is an exploratory research, with qualitative approach, which has as data collect instrument the bibliographic and the documental research. It approaches the information concepts and its paradigms and how these paradigms influence Information Science, its concept and subareas. It has as results the fact that Information Literacy has three distinct approaches according to the information paradigms and a custodial approach: 1 - custodial, connected to the concept of Bibliographic Instructionl; 2 - physical, which comprehends the Information Literacy under a view of access $f$ documents and data; 3 - cognitive, which comprehends the role of the satisfaction of the individual's information needs; and 4 - social view, that understand the role of the Information Literacy as important to individual's social, political, ethical and political background. Concludes that Information Literacy presented distinct characteristics at the same time information theories developed, emphasizing sometimes the physical aspects of information, sometimes its cognitive aspects and also its social aspects.
\end{abstract}

Palavras-chave: Information Literacy. Information Theory. Information Science.

InCID: R. Ci. Inf. e Doc., Ribeirão Preto, v. 11, n. 2, p. 185-205, set. 2020/fev. 2021.

DOI: 10.11606/issn.2178-2075.v11i2p185-205 


\section{Introdução}

A Ciência da Informação surge como área do conhecimento que busca oferecer reflexões conceituais, teóricas e metodológicas sobre a informação, as tecnologias da informação e do conhecimento e os aspectos cognitivos e sociais que estão atrelados ao universo informacional. De acordo com Borko (1968, p. 1, tradução nossa),

Ciência da Informação é a disciplina que investiga as propriedades e o comportamento da informação, as forças que governam o fluxo informacional, e os meios de processamento da informação para otimizar sua acessibilidade e usabilidade. Diz respeito a um corpo de conhecimentos relacionados à geração, coleta, organização, armazenamento, recuperação, interpretação, transmissão, transformação e utilização da informação.

Herdeira das discussões de autores como Paul Otlet, Henri La Fontaine, Vannevar Bush e de eventos como a Conferência de Informação Científica da Royal Society (QUEIROZ; MOURA, 2015), a conceituação de Ciência da Informação trazida por Borko (1968) aponta para o fato de que áreas como a Biblioteconomia e a Documentação deveriam se dedicar aos estudos dos conteúdos e das mensagens e não apenas ao estudo dos registros do conhecimento.

Wersig e Nevelling (1975 apud Saracevic, 1996, p. 43) apontam para o fato de que a Ciência da Informação tem a responsabilidade social de refletir sobre os problemas informacionais, uma vez que ela se desenvolveu "[...] historicamente porque os problemas informacionais modificaram completamente sua relevância para a sociedade [...]”"

Desde então a Ciência da Informação vem se desenvolvendo enquanto área do conhecimento que estuda uma grande diversidade de problemas informacionais, destacando-se, dentre elas: a comunicação científica, estudo de usuários, economia política da informação, bibliometria, representação e recuperação da informação e gestão da informação e do conhecimento (ARAÚJO, 2014).

A Ciência da Informação, entretanto, não se manteve estática ao longo dos anos, sendo perceptíveis mudanças paradigmáticas em períodos distintos nos estudos informacionais. Capurro (2003) aponta que pelo menos três paradigmas diferentes podem ser identificados na história da área: o físico, em que a informação é entendida como algo objetivo e material; o cognitivo, em que informação e conhecimento estão entrelaçados e existe uma necessidade de se focar no usuário; e o social, em que a informação é vista como fenômeno social, atrelado a questões políticas, econômicas e culturais, por exemplo. 
A divisão da Ciência da Informação em subáreas e as inúmeras conceituações provenientes das diferentes abordagens sobre o conceito de informação são essenciais para a constante inovação na área, com o surgimento contínuo de novas temáticas de estudo sobre informação, como é o caso da Competência em Informação.

Em linhas gerais, a Competência em Informação pode ser entendida como um conjunto de habilidades que torna o indivíduo capaz de "[...] reconhecer sua própria necessidade de informação e localizar, avaliar e usar efetivamente a informação de que precisa" (AMERICAN LIBRARY ASSOCIATION, 1989, tradução nossa). O desenvolvimento dessas habilidades permitiria aos sujeitos lidar criticamente com a informação, aprender a aprender e participar ativamente da Sociedade da Informação.

O presente artigo tem como objetivo relacionar as teorias da informação ao discurso de Competência em Informação, indagando-se de que maneira os paradigmas relacionados ao Conceito de Informação influenciaram e influenciam os estudos de Competência em Informação. Trata-se de uma pesquisa do tipo exploratória, de abordagem qualitativa, que possui como instrumento de coleta de dados a pesquisa bibliográfica e documental, que auxiliaram na reunião de corpus teórico para relacionar as Teorias da Informação aos Conceitos de Competência em Informação.

\section{O conceito de informação}

O conceito de informação é anterior ao surgimento da Ciência da Informação, sendo percebido o seu uso no Ocidente, desde a Antiguidade Clássica. De acordo com Capurro e Hjorland (2007, p. 156), o “Thesaurus Linguae Latinae (1990) dá referências detalhadas dos usos em latim de informatio e informo desde Virgílio (70-19 A.C sic) até o século VIII".

Segundo Capurro e Hjorland (2007), o conceito de informação na Antiguidade Clássica e na Idade Média esteve atrelado à definição original do termo, ou seja, informação como 'ato de dar forma a algo' e acrescentam ainda que existem, de acordo o Thesaurus Linguae Latina (1990 apud CAPURRO; HJIOLARND, 2007), dois contextos básicos para o uso dessa definição. O contexto tangível diz respeito ao 'ato de dar forma a coisas ou pessoas' (como um bebê no ventre da mãe). Por sua vez, no contexto intangível, evidencia-se a ideia de informar como 'formar alguém moralmente' através de uma educação que venha a adequar indivíduos ao modelo da sociedade. 
Com a chegada da Idade Moderna, o conceito de informação assume novas significações, começando a ser entendido ‘o ato de como comunicar algo a alguém'. Capurro e Hjorland (2007) apontam que as correntes filosóficas racionalistas e empiristas modernas já demonstram um deslocamento do conceito material de 'dar forma', para um conceito em que as fontes de conhecimento (as ideias, no caso racionalista; e as sensações, no caso dos empiristas) passam a informar a cognição dos indivíduos. Estar informado deixou de significar, a partir de então, 'moldado por', vindo a significar 'relatos recebidos de'.

O conceito de informação, dessa forma, passou por uma transformação com raízes e efeitos sociais, culturais e filosóficos, que passaram de um ato de dar forma a algo no sentido material, para o ato de um mestre "dar forma" ao seu pupilo (formar) e, enfim, ao ato de transmitir informação de um emissor a um receptor, sentido esse que estaria no cerne do desenvolvimento da Ciência da Informação séculos depois.

\subsection{Paradigma custodial da informação}

As teorias atualmente conhecidas que tratam de informação possuem raízes em várias áreas do conhecimento, como Biblioteconomia, a Arquivologia e a Museologia, uma vez que são resultantes do ato humano de produzir registros materiais de conhecimentos e que surgem como disciplinas que se dedicam a custodiar tais registros produzidos pela humanidade e fortalecer a criação de " [...] instituições dedicadas a salvaguardá-los (que deram origem ao que atualmente são os arquivos, as bibliotecas e os museus) e regras para organizar esses documentos" (ARAÚJO, 2014, p. 2).

Essa visão custodial vai permear a maior parte de história da Biblioteconomia, da Arquivologia e da Museologia e ter proeminência na criação de instituições para salvaguardar documentos específicos, como arquivos, bibliotecas e museus, cujas "[...] tarefas e exigências práticas [...] se sobrepunham a eventuais preocupações teóricas e reflexivas" (SILVA, 2009, p. $11)$.

O paradigma custodial, identificado por Silva $(2009$, p. ) ainda como patrimonialista, historicista e tecnicista, tem como características assim o fato de que

Os documentos eram objectos físicos e, ao mesmo tempo, fontes indispensáveis à produção de ciência e à valorização da cultura de um povo. Guardar os documentos antigos e raros tornou-se a missão primeira e última dos profissionais, colocados nas instituições culturais [...]. Por outro lado, a consciência do acesso aos conteúdos, que 
decorria da função original consignada, para Arquivos e Bibliotecas, nas leis revolucionárias de setecentos, era contraditória (os documentos deviam estar acessíveis a todos, mas nem todos os mereciam...) e esbarrou em obstáculos de diversa ordem [...] que a atrofiaram até ao surgimento da Era da Informação em que já estamos em pleno.

Apesar disso, segundo Hjorland (2014, p. 3-4), o conceito de documento, inserido no contexto da Documentação de Paul Otlet e Henri La Fontaine, abrirá espaço para se discutir uma nova proposta, que seria o conceito de informação. Fotografias, discos, cartões postais, microfilmes (e até mesmo seres vivos) passam a ser considerados registros e fontes de conhecimento tanto quanto livros, trazendo assim novas perspectivas sobre o armazenamento, a organização e o acesso à informação.

As discussões sobre o conceito de informação e de seu papel na sociedade, transcendendo a ideia dos documentos, porém, só serão percebidas ao longo do desenvolvimento da Ciência da Informação, principalmente devido à multiplicidade de abordagens e a possibilidade de distinguir tais abordagens em três paradigmas: físico, cognitivo e social.

\subsection{Paradigma físico da informação}

As primeiras discussões sobre o conceito de informação, de acordo com Capurro (2003, sem paginação), estão relacionadas ao que ele chama de "Paradigma Físico". O paradigma físico é uma abordagem que reúne as concepções de informação, que as entendem como objetivo material, postulando "[...] que há algo, um objeto físico, que um emissor transmite a um receptor".

Para Capurro (2003, sem paginação), a Teoria Matemática da Informação de Shannon e Weaver (1948) e os experimentos de Cranfield, em 1957, que tinham como objetivo "[...] medir os resultados de um sistema computadorizado de recuperação da informação", são os principais exemplos desse paradigma. De acordo com Hjorland (2014, p. 6, tradução nossa) a teoria de Shannon e Weaver tratava-se, por exemplo, de “[...] uma teoria matemática sobre questões tecnológicas presentes sempre que dados são transmitidos, armazenados ou recuperados” (HJORLAND, 2014, p. 6, tradução nossa).

A teoria de Shannon entendia a informação como sinal, uma mensagem a ser transmitida, dentro de um sistema aberto. De acordo com Capurro e Hjorland (2007, p. 163), "o modelo de Shannon [...] inclui seis elementos: uma fonte, um codificador, uma mensagem, 
um canal, um decodificador e um receptor". Esses elementos ressaltam o fato de que a informação é um conteúdo que pode ser codificado e, através de um meio de comunicação, transmitida diretamente a um receptor, que a receberá assim como foi enviada.

Araújo (2010) identifica a influência do paradigma físico na Ciência da Informação com a necessidade de criação de melhores linguagens e sistemas de recuperação da informação, estudos de usuários focados no levantamento do uso dos recursos informacionais, acesso à informação como acesso físico aos registros do conhecimento, preocupação com a identificação de tipologias informacionais formais e informais.

\subsection{Paradigma cognitivo da informação}

Influenciado inicialmente pelas ideias de Karl Popper e posteriormente pelas teorias provenientes da Psicologia e das Ciências Cognitivas, o paradigma cognitivo da informação, de acordo com Capurro (2003, sem paginação), distingue-se do paradigma físico por tratar de “[ ... ver de que forma os processos informativos transformam ou não o usuário, entendido em primeiro lugar como sujeito cognoscente possuidor de „modelos mentais“ do „mundo exterior“ que são transformados durante o processo informacional".

Dentre os principais autores neste paradigma, pode-se destacar Igwersen, Pertti Vakari, Belkin, quem definiu o conceito de estado anômalo do conhecimento, e Brookes (1980) que identificou a necessidade de se relacionar a informação e conhecimento, ressaltando o papel do indivíduo no processamento mental da informação. Para isso, ele

[...] expressou esse relacionamento [entre informação e conhecimento] por meio do que ele chamou de 'equação fundamental': $K[S]+\Delta I=K[S+\Delta S]$ que afirma, de modo geral, que a estrutura do conhecimento $\mathrm{K}[\mathrm{S}]$ é transformada em uma nova estrutura [de conhecimento] modificada $\mathrm{K}[\mathrm{S}+\Delta \mathrm{S}]$ pela informação $\Delta \mathrm{I}$, o $\Delta \mathrm{S}$ indicando o efeito da modificação (BROOKES, 1980, p. 131, tradução nossa).

A equação fundamental de Brookes pode ser definida enquanto um modelo (nãomatemático) que busca representar como se dá o processo de transformação da informação em conhecimento. De acordo com a equação, o indivíduo que já está em um estado de conhecimento específico, quando recebe informação, tem seu estado de conhecimento alterado.

De acordo com Araújo (2010, p. 103), o modelo cognitivo influenciou os estudos da Ciência da Informação, redirecionando o foco inicial das fontes de informação para os usuários. Essa mudança ocasionou, por exemplo, a incorporação do conhecimento na forma de 
representar, os estudos de usuários passaram a se preocupar com o comportamento informacional dos indivíduos, como estes identificam lacunas e que estratégias utilizam para superá-las.

\subsection{Paradigma social da informação}

O paradigma social da informação surge nas décadas mais recentes como uma crítica aos modelos físico e cognitivo utilizados até então na Ciência da Informação, tendo em vista principalmente o fato de que esses dois últimos paradigmas extraem os sujeitos e os processos informacionais (como produção, circulação e uso da informação) da estrutura sociocultural no qual estão inseridos.

De acordo com Capurro (2003, sem paginação), a proposta é realizar “[...] uma integração da perspectiva individualista e isolacionista do paradigma cognitivo dentro de um contexto social no qual diferentes comunidades desenvolvem seus critérios de seleção e relevância”, enfatizando o fato de que, segundo Hjorland (2003 apud CAPURRO, 2003, sem paginação) o " [...] objeto da ciência da informação é o estudo das relações entre os discursos, áreas do conhecimento e documentos em relação às possíveis perspectivas ou pontos de acesso de distintas comunidades de usuários".

De acordo com Araújo (2014, p. 17), a realização do I CoLis (International Conference on Conceptions of Library and Information Science), em 1991, trouxe novas abordagens na discussão sobre o conceito de informação, estabelecendo que

[...] esse "algo" identificado como "informação", obtido no processo de interação entre dados e conhecimento, não era definida apenas pelo sujeito específico, um sujeito individual, isolado, destacado do mundo e do convívio com outros. Antes, os contextos específicos (as realidades históricas, políticas, econômicas, culturais) são parcialmente dominantes do processo [informativo].

Esse novo paradigma permite que se vá além de uma concepção de informação como objeto ou de informação como somente aquilo que é processado mentalmente por um indivíduo. As estruturas socioculturais influenciam a produção, a circulação, a recepção, a compreensão, a criação, a organização e a disseminação da informação.

Araújo (2010) identifica que, dentre as influências do paradigma social na pesquisa em Ciência da Informação, pode-se destacar: a construção coletiva de sistemas de recuperação da informação, estudos de usuários voltados para as práticas informacionais de indivíduos e 
comunidades, a cultura organizacional no âmbito da Gestão da Informação e do Conhecimento, estudo dos regimes de informação, redes de produção do conhecimento científico e a análise de domínio.

Os paradigmas da Ciência da Informação, porém, não restringiram sua influência apenas para os campos de estudos tradicionais, como recuperação e representação da informação ou estudos de usuários. É perceptível ver tal influência também em temáticas relativamente mais recentes como é o caso da "Competência em Informação".

\section{Competência em informação sob a visão dos paradigmas da Ciência da Informação}

O presente artigo entende que a história da Competência em Informação também pode ser estudada sob a visão dos paradigmas da Ciência da Informação de Capurro (2003), incluindo também o paradigma custodial de Silva (2009), uma vez que a temática está inserida dentro das discussões sobre o acesso, a avaliação e o uso da informação.

Dessa forma, a Competência em Informação, assim como a Ciência da Informação e suas subáreas, pode ter seu percurso histórico abordado de acordo com os paradigmas da informação, apresentando uma primeira fase em que o tema era encarado sob uma perspectiva física da informação, uma segunda fase em que se destacava uma visão mais cognitiva, uma terceira fase que considerou a perspectiva social na produção, disseminação e uso da informação e incluindo-se também uma fase anterior às demais chamada custodial.

Um trabalho com uma perspectiva similar pode ser encontrado em Dudziak (2003, p. 30). Ela aponta que "a partir da análise da evolução do conceito, três concepções de information literacy se destacam: a concepção da informação [...]; a concepção cognitiva [...]; a concepção da inteligência [...]".

Nesse sentido, esse estudo teve como base os paradigmas da informação de Rafael Capurro (2003) o conceito de paradigma custodial de Silva (2009) e as concepções de Competência em Informação de Dudziak (2003). 


\subsection{Concepção ou nível custodial: ênfase uso das fontes de informação}

A Competência em Informação surge como a necessidade de se empreender ações educativas para que os indivíduos possam acessar e usar a informação no contexto de explosão informacional vivenciado principalmente nas últimas décadas do século XX (ZURKOWSKI, 1974).

Entretanto, de acordo com Campello (2003, p. 29), essas já acontecem eram perceptíveis nas bibliotecas, tendo em vista o surgimento dos Serviços de Referência e também do conceito de Educação de Usuários que "até a década de 1950, [...] praticamente não existia nas bibliotecas escolares americanas". É justamente em meados da década de 1950, que se viu surgirem iniciativas chamadas de bibliographic instruction, um tipo de instrução bibliográfica voltada a tornar o usuário apto a utilizar o acervo ${ }^{1}$.

Na década seguinte, no início dos anos 1960, sob as recomendações da American Association of School Librarians (AASL), uma abordagem de educação de usuários, em que o a instrução bibliográfica fosse incluída e adaptada ao currículo escolar foi criada $^{2}$, sendo acompanhada logo em seguida por uma visão de Educação de Usuários que enfatizava “[...] habilidades de questionamento e solução de problemas” (CAMPELLO, 2003, p. 29).

Apesar de anterior ao conceito de Competência em Informação corrente, a Educação de Usuários pode ser entendida como um pré-paradigma do campo, pois oferece subsídios para o seu desenvolvimento teórico e metodológico posterior. Classifica-se aqui como concepção ou nível custodial com ênfase nas fontes de informação, porque a Educação de Usuários, ainda que ao longo do tempo passou a focar na aprendizagem, esteve ligada à biblioteca e os seus recursos, buscando tornar os indivíduos aptos a utilizá-los ou inseri-los no currículo escolar.

O próximo passo seria então perceber o fato de que o que os usuários têm necessidade, buscam, avaliam e usam não somente os materiais bibliográficos, mas a informação propriamente dita, existente nos mais variadas fontes e recursos, conclamando assim a classe bibliotecária a encontrar um novo meio de inserir os usuários em um ambiente cada vez mais mediado por informação: a Competência em Informação.

\footnotetext{
${ }^{1}$ Sendo conhecida como "abordagem na fonte", por Kulthau (1987 apud CAMPELLO, 2003) e "foco na coleção", por Stripling (1996 apud CAMPELLO, 2003).

${ }^{2}$ Sendo conhecida como "abordagem guia", por Kulthau (1987 apud CAMPELLO, 2003) e "foco no programa", por Stripling (1996 apud CAMPELLO, 2003).
}

InCID: R. Ci. Inf. e Doc., Ribeirão Preto, v. 11, n. 2, p. 185-205, set. 2020/fev. 2021. 


\subsection{Concepção ou nível da informação: ênfase nas tecnologias da informação}

A ideia de Competência em Informação surge nos Estados Unidos na década de 1970, originalmente apresentada sob o nome de information literacy, tendo como pressupostos o fato de que os programas de educação de usuários em bibliotecas deveriam estar mais preocupados em fazê-los aptos a usar a informação em todos os seus suportes e fontes e como uma forma de trazer as discussões sobre letramento para o âmbito informacional (BEHRENS, 1994).

Também com a proliferação de fontes de informação disponíveis no mercado sobre os mais diversificados assuntos, foi Paul Zurkowski, presidente da Associação Americana de Indústrias (IAA), quem propôs, pela primeira vez, no documento "The Information Service Environment Relationships and Priorities", em novembro de 1974, apresentado à americana National Comission on Library and Information Science, o conceito de information literacy.

Marcada por uma visão que compreendia o acesso e uso da informação como algo vinculado diretamente a bases de dados, de documentos e de fontes de informação, o relatório Paul Zurkowski (1974) definia a necessidade de que no contexto americano se empreendessem ações governamentais em prol de uma educação que salientasse o acesso à informação.

Apesar de que sob a influência de perspectivas cognitivistas sobre o conceito de informação ${ }^{3}$, Zurkowski (1974) entendia que a Competência em Informação deveria ser tida como a habilidade de conhecer as fontes de informação e saber utilizá-las para a resolução de problemas e a tomada de decisão. Para ele,

\footnotetext{
Pessoas treinadas na aplicação de fontes de informação em seu trabalho podem ser chamadas competentes em informação. Eles têm aprendido técnicas e habilidades para utilizar uma grande gama de ferramentas informacionais tanto quanto fontes primárias de informação moldando solucões informacionais para os seus problemas (ZURKOWISKI, 1974, p. 5, tradução nossa).
}

Dessa forma, a Competência em Informação teria como grande propósito tornar os cidadãos competentes para acessar, avaliar e usar informação de maneira autônoma e crítica, não mais como meros usuários da informação, mas como atores na sociedade da informação cada vez mais tecnológica e com superabundância informacional.

\footnotetext{
${ }^{3}$ Zurkowski (1974, p. 1) entendia que a informação poderia ser conceituada como "[...] conceitos ou ideias que ao entrar no campo da percepção pessoal são avaliadas e assimiladas, reforçando ou modificando o conceito do indivíduo sobre a realidade e/ou habilidade para agir". Essa conceituação de informações lembra a Equação Fundamental de Brookes (BROOKES, 1980), que fala sobre a informação como um processo de mudança de estrutura do conhecimento do indivíduo.
} 
A proposta da Competência em Informação foi ativamente desenvolvida após a publicação de Zurkowski em 1974. Cees Hamelink e Major Owens, ambos em 1976, de acordo com Behrens (1994), trouxeram novas visões sobre a necessidade de os indivíduos saberem acessar, avaliar e usar a informação para a resolução de problemas e a tomada de decisão. Owens (1976, p. 27, tradução nossa), em um artigo que entrelaça bibliotecas, informação, cidadania e incentivos governamentais, ressalta o papel da Competência em Informação para a democracia, pois a

Competência em Informação é necessária para garantir a sobrevivência de instituições democráticas. Todos os homens são criados iguais mas votantes com recursos informacionais estão em posição de fazer decisões mais inteligentes do que cidadãos não competentes em informação. A aplicação de recursos informacionais no processo de tomada de decisão.

A contribuição de Owens para a Competência em Informação foi de extrema importância para trazer a discussão sua dimensão social. Além de uma formação voltada para o uso de fontes de informação para a resolução de problemas e a tomada de decisão no contexto acadêmico, no trabalho e na indústria, é necessário compreender o papel que a Competência em Informação possui em formar cidadãos críticos, que tomam decisões inteligentes ao votar e utilizam a informação para efetivar suas responsabilidades civis.

Behrens (1994, p. 136, tradução nossa) destaca que a década de 1970 foi para a Competência em Informação essencial para lançar os seus fundamentos, enquanto “[...] um novo conjunto de habilidades para a utilização eficiente e efetiva da informação e suas ferramentas de acesso e o uso ou aplicação das informações encontradas para a resolução de problemas". Mostrando o seu papel crucial no desenvolvimento de habilidades e competências para viver em uma sociedade cada vez mais imersa em informação.

Essas abordagens iniciais sobre a Competência em Informação estão alinhadas ao que Dudziak (2003) chama de concepção ou nível da informação com ênfase na tecnologia da informação. Essa concepção aponta que

Associada à sociedade da informação, marcada pela forte influência da tecnologia, o conceito de competência em informação é definido como a pesquisa, estudo e aplicação de técnicas e procedimentos ligadas ao processamento e distribuição de informações com base no desenvolvimento de habilidades no uso de ferramentas e suportes tecnológicos (DUDZIAK, 2003, p. 30).

Além de habilidades tecnológicas, Dudziak (2003, p. 30) afirma que essa concepção de Competência em Informação aponta a biblioteca "[...] como suporte ao ensino/pesquisa e proporciona o acesso físico à informação organizada", podendo esta 
concepção estar atrelada ao Paradigma Físico da Informação, em que a informação é tida como algo objetivo e material, externo ao indivíduo e Competência em Informação é entendida então como um conjunto de habilidades para identificar e acessar fontes de informação, físicas ou digitais, e usá-las para a resolução de determinados problemas.

\subsection{Concepção ou nível do conhecimento: ênfase nos processos cognitivos}

A Competência em Informação viu surgir, na década de 1980, as primeiras ações sistemáticas para a discussão teórica sobre o seu conceito, ao mesmo tempo atrelando-as direta ou indiretamente às novas tecnologias da informação e da comunicação, à consolidação de sua ligação com o conceito de letramento e de aprendizado ao longo da vida, o papel de atitudes particulares (ex.: consciência, desejo, apreciação e aplicação acurada) ao lidar com a informação e do pensamento crítico na compreensão e avaliação da informação (BEHRENS, 1994).

Além disso, percebe-se que o conceito de Competência em Informação que antes correspondia somente a acessar e usar informação efetivamente, com os avanços da década de 80, começa a abranger novas habilidades como: saber que possui necessidade de informação, avaliar criticamente as informações obtidas e organizá-las.

A década de 80 se encerra com a publicação do Presidential Comitee on Information Literacy: Final Report, produzido pela American Library Association, ALA, em 1989. O relatório teve como finalidade lançar as bases oficiais sobre a temática que seriam intensivamente trabalhadas nos 30 anos seguintes e elenca, entre as habilidades informacionais, que um estudante deve possuir para ser competente em informação:

- saber quando tem necessidade de informação.

- identificar a informação da qual necessita para resolver um problema ou uma questão.

- encontrar a informação de que precisa e avaliar informação.

- organizar a informação.

- usar a informação efetivamente para resolver um problema ou questão. (AMERICAN LIBRARY ASSOCIATION, 1989, online, tradução nossa).

Com as habilidades definidas no Final Report e atrelando a Competência em Informação a conceitos como aprendizagem independente e responsabilidade social, o documento apresentaria fatores chaves para a consolidação da temática nos anos seguintes e 
sua aplicação por meio, por exemplo, da criação de padrões e modelos em escolas e universidades.

Dentre as principais autoras relacionadas à temática neste período está Carol Kuhlthau, que lançou em 1991 o modelo "Information Search Process". De orientação construtivista o modelo apontava que questões afetivas, cognitivas e físicas estavam diretamente relacionadas ao processo de busca por informação.

Crespo e Caregnato (2003, p. 250-251) acrescentam ainda que

Para Kuhlthau (1991) o processo de busca de informação é centrado no indivíduo, formando-se através da construção pessoal, na qual o usuário parte da informação para criar novos conhecimentos. Esta concepção foi baseada nas idéias de autores como George Kelly, R. S. Taylor e N. J. Belkin.

Dessa forma, ao apresentar o processo de busca de informação como compreendido em seis fases (1 - Iniciar, 2 - Selecionar, 3 - Explorar, 4 - Formular, 5 - Coletar e 6 - Apresentar), Kuhlthau (1991 apud CRESPO; CAREGNATO, 2003) acrescenta ainda que ao longo desse processo o aluno deve lidar com questões emocionais (como ansiedade, incerteza e confiança) e com questões cognitivas e atitudinais (como reconhecer que possui uma lacuna de conhecimento e explorar determinado tópico).

Junto com outros modelos como o Big Six de Einsenberg e Burkowiski, o 8W de Annete Lamb e os modelos Information Power e Standards for Higher Education da ALA, a proposta de Carol Kuhlthau se tornaram essenciais para a consolidação da Competência em Informação no contexto biblioteconômico e a necessidade de aliar conhecimentos relativos à Ciência da Informação e à Biblioteconomia às teorias pedagógica vigentes, como meio de inserir as habilidades na formação dos indivíduos seja no contexto acadêmico ou ao longo da vida.

Essa segunda fase da Competência em Informação pode ser identificada como a concepção ou nível do conhecimento com ênfase nos processos cognitivos apontado por Dudziak (2003, p. 30), uma vez que nesse período os estudos de Competência em Informação estavam preocupados com "[...] a construção de modelos mentais, não apenas respostas às perguntas. O foco está no indivíduo, em seus processos de compreensão da informação e seu uso em situações particulares".

Essa concepção está atrelada ao Paradigma Cognitivo da Informação de Capurro (2003), em que o foco da Ciência da Informação é transferido da informação como objeto para informação como processo de aquisição de conhecimento. A Competência em Informação é 
entendida então como o processo de busca e uso da informação, que envolve questões cognitivas, afetivas e atitudinais e que culmina na agregação de novos conhecimentos à base inicial dos indivíduos.

3.4. Concepção ou nível da aprendizagem: ênfase no aprendizado ao longo da vida

A Competência em Informação tem experimentado desde o início dos anos 2000 a expansão de seu conceito, principalmente sob a tutela da UNESCO e da IFLA, com ações relacionadas primeiramente ao Aprendizado ao Longo da Vida e mais recentemente ao conceito de Competência Informacional e Midiática. Porém cabe destacar que o surgimento de novas abordagens como o Multiletramento e o Metaletramento, encontrado em documentos da ALA, a visão multidimensional de Vitorino e Piantola (2009) e o uso da Teoría Crítica têm afetado os estudos contemporâneos sobre Competência em Informação.

A União das Nações Unidas para a Educação, a Ciência e a Cultura (UNESCO) e a Federação Internacional de Associações Bibliotecárias (IFLA), através do Projeto Informação para Todos, iniciaram ações sistemáticas para a internacionalização e implementação da Competência em Informação no mundo, atrelando-a incialmente ao conceito de Aprendizado ao Longo da Vida e entendendo-as como "[...] os faróis da Sociedade da Informação, iluminando os caminhos para o desenvolvimento, a prosperidade e a liberdade" (FARÓIS... 2005).

A ideia de atrelar a Competência em Informação ao Aprendizado ao Longo da Vida, que já era percebida nas décadas de 80 e 90 (BEHRENS, 1994) permite compreender o papel que a Competência em Informação possui não apenas no contexto escolar, mas na formação de indivíduos, inseridos em um contexto social maior chamado Sociedade da Informação, em que a informação molda as práticas educacionais, trabalhistas e culturais cotidianas.

Nos últimos anos, porém, ambas a UNESCO e a IFLA vêm trabalhando na popularização e aplicação do conceito de Competência Informacional e Midiática. A proposta, que une as reflexões sobre Competência em Informação e Mídia-Educação, é entender que os indivíduos na Sociedade da Informação precisam possuir “[...] as competências necessárias para a vida no século XXI e a necessidade de lidar com enormes volumes de dados, informações e mensagens de mídia viabilizados por diferentes plataformas e provedores de informação e comunicação" (MARCO..., 2016, p. 30). 
A proposta, de acordo com Borges (2017, p. 31), é entender que, além das competências informacionais tradicionais e da "[...] criticidade necessária sobre [a] própria produção [dos produtos midiáticos], emergem aspectos de distribuição (quem é o público da produção?), de participação (com quem engajar-se?), de criação (com quem produzir?)". Os indivíduos deixariam de ser apenas consumidores de informação e passariam a se tornar prossumidores, ou seja, ao mesmo tempo produtores e consumidores de conteúdo.

Por outro lado, no âmbito da Associação Americana de Bibliotecas (ALA), dois conceitos têm despontado como referência para os estudos contemporâneos sobre Competência em Informação: o Multiletramento e o Metaletramento.

Ambos os termos compreendem que a Competência em Informação pode ser considerada como um conceito guarda-chuva que engloba a aquisição de múltiplos letramentos (ou competências), como “[...] a digital, a visual, a textual e a tecnológica, que são de aquisição cruciais para que todos os estudantes tenham êxito em nossa sociedade rica em informação" (AMERICAN ASSOCIATION OF SCHOOL LIBRARIES, 2009, p. 8, tradução nossa). Entretanto o Metaletramento

oferece uma visão renovada da Competência em Informação como um conjunto abrangente de habilidades em que estudantes são consumidores e criadores de informação que podem participar com êxito em espaços colaborativos [e] demanda engajamento comportamental, afetivo, cognitivo e metacognitivo com o ecossistema informacional (FRAMEWORK, 2016, p. 1-2, tradução nossa).

O conceito de Metaletramento traz assim a possibilidade de se incluir no desenvolvimento de habilidades informacionais, habilidades para produzir informação, utilizar novas mídias e recursos, participar em comunidades colaborativas e redes de conhecimento e inserir-se integralmente na Sociedade da Informação.

Esse novo arcabouço teórico ofereceu subsídios para se criar modelo de Competência em Informação voltado para o Ensino Superior pela Association of College and Research Libraries (ACRL), o Framework de Competência em Informação para o Ensino Superior. No documento a Competência em Informação é entendida como

[...] um conjunto de habilidades integradas que abrange a descoberta reflexiva da informação, a compreensão de como a informação é produzida e valorada, e o uso da informação na criação de novos conhecimentos e a participação ética em comunidades de aprendizagem (FRAMEWORK..., 2016, p. 3, tradução nossa).

O documento não se prende à apresentação de padrões nem de indicadores de performance que supostamente deveria ser apresentados por um indivíduo para identificá-lo 
como competente em informação, mas relaciona um conjunto de conceitos que salientam o fato de que a informação, sua produção, acesso e uso são atividades resultantes de fenômenos sociais, culturais, econômicos e políticos, que vão além das experiências cognitivas individuais, e que a Competência em Informação estaria relacionada a ter uma visão avaliativa crítica sobre todo o processo de produção, organização e uso da informação.

Entretanto, de acordo com Vitorino e Piantola (2009), autores como Shapiro e Hughes, Elmborg e Doherty, já estavam desenvolvendo uma abordagem crítica para a Competência em Informação, que atrelasse o conceito às teorias educacionais de Paulo Freire e entendesse o seu papel na formação para a cidadania e para o ativismo.

De acordo com Doyle (2018, p. 27), ainda sem uma definição única e referendada, pode-se dizer que competência crítica
em informação é uma linha de estudos que: a) critica visões, pesquisas ou projetos
ideologizantes de competência em informação; b) integra elementos da teoria crítica
da sociedade e da pedagogia crítica (de Paulo Freire) em suas reflexões e práticas, e;
c) se propõe a combater os efeitos nefastos do capital sobre a circulação de informação
na sociedade. [...] Ao integrar essas três dimensões, o conceito de competência crítica
em informação engloba reflexão, crítica e ação.

No caso da Competência Crítica em Informação, a proposta é de que a Competência em Informação não seja tida como neutra, assim como a produção, a organização, a disseminação e o acesso a informação não o são. Que os indivíduos competentes em informação saibam lidar criticamente com a informação disponível e usá-la de maneira reflexiva como meio de facilitar a criação de espaços democráticos de acesso a direitos, saúde, trabalho e educação para todos.

Por fim, é interessante mencionar o trabalho de Vitorino e Piantola (2011) na esquematização das 4 Dimensões da Competência em Informação. Elas apontam (Quadro 1) que a Competência em Informação pode ser entendida como constituída de múltiplas dimensões (técnica, estética, ética e política), que não se excluem, mas são igualmente necessárias para definir e traçar as habilidades, conhecimentos, atitudes e valores que envolvem o acesso, a avaliação e o uso da informação. 
Quadro 1 - Resumo das características das dimensões da competência informacional

\begin{tabular}{|c|c|c|c|}
\hline Dimensão técnica & Dimensão estética & Dimensão ética & Dimensão política \\
\hline $\begin{array}{l}\text { Consiste nas habilidades } \\
\text { adquiridas para } \\
\text { encontrar, avaliar e usar } \\
\text { a informação de que } \\
\text { precisamos. } \\
\text { Ligada à ideia de que o } \\
\text { indivíduo competente } \\
\text { em informação é aquele } \\
\text { capaz de acessar com } \\
\text { sucesso e dominar as } \\
\text { novas tecnologias. }\end{array}$ & $\begin{array}{l}\text { Criatividade sensível. } \\
\text { Capacidade de } \\
\text { compreender, } \\
\text { relacionar, ordenar, } \\
\text { configurar e ressignificar } \\
\text { a informação. } \\
\text { Experiência interior, } \\
\text { individual e única do } \\
\text { sujeito ao lidar com os } \\
\text { conteúdos de } \\
\text { informação e sua } \\
\text { maneira de expressá-la e } \\
\text { agir sobre ela no âmbito } \\
\text { coletivo. }\end{array}$ & $\begin{array}{l}\text { Uso responsável da } \\
\text { informação. } \\
\text { Visa à realização do } \\
\text { bem comum. } \\
\text { Relaciona-se a questões } \\
\text { de apropriação e uso da } \\
\text { informação, tais como } \\
\text { propriedade intelectual, } \\
\text { direitos autorais, acesso } \\
\text { à informação e } \\
\text { preservação da memória } \\
\text { do mundo. }\end{array}$ & $\begin{array}{l}\text { Exercício da cidadania. } \\
\text { Participação dos } \\
\text { indivíduos nas decisões } \\
\text { e nas transformações } \\
\text { referentes à vida social. } \\
\text { Capacidade de ver além } \\
\text { da superfície do } \\
\text { discurso. } \\
\text { Considera que a } \\
\text { informação é produzida } \\
\text { a partir de (e em) um } \\
\text { contexto específico. }\end{array}$ \\
\hline
\end{tabular}

Fonte: VITORINO; PIANTOLA (2011, p. 109).

O quadro de Vitorino e Piantola (2011) estabelece que não se deve esquecer nenhuma dimensão da Competência em Informação em detrimento da outra, pois para que um indivíduo seja considerado competente em informação ele deve ao mesmo tempo saber habilidades técnicas para acessar e usar informações, ter sensibilidade estética para apreciar e criar conteúdos informacionais, utilizar as informações para participar como cidadão na sociedade democrática e tomar postura ética quanto ao uso, a apropriação e a distribuição da informação.

A terceira fase da Competência em Informação pode ser identificada, assim, como a concepção ou nível da inteligência com ênfase no aprendizado ao longo da vida, como apontado por Dudziak (2003, p. 30), uma vez a aprendizagem neste nível é entendido como fenômeno social e a Competência em Informação preocupada em "[...] considerar a dimensão social e ecológica do aprendiz, percebendo-o não mais como usuário, nem tampouco como indivíduo antes como sujeito, que é o indivíduo enquanto ator social, cidadão".

Essa conceituação se encaixa com o Paradigma Social da Informação de Capurro (2003), em que a informação é vista como fenômeno social e inserida dentro de estruturas sociais de poder político, econômico e cultural. A Competência em Informação é entendida como um conjunto de habilidades que abrangem uma variada quantidade de letramentos e competências que influenciam na aprendizagem dos indivíduos e que os prepara para refletir criticamente sobre o ciclo informacional, produzir conteúdos e atuar eticamente como cidadão em uma sociedade democrática mediada por informação. 
Dessa forma, assim como a Ciência da Informação e suas subáreas, a Competência em Informação também sofre influência das teorias da informação vigentes, inserindo-se no contexto dos estudos informacionais como forma de se adaptar às discussões da área e, também, de oferecer modelos conceituais, teóricos e metodológicos inovadores e relevantes ao estudo de fenômenos contemporâneos.

\section{Considerações finais}

Dentre as reflexões científicas trazidas pela Ciência em Informação estão aquelas voltadas ações que permitam o desenvolvimento de habilidades que facilitem o acesso, a avaliação e o uso da informação, consideradas essenciais para o dia a dia de um indivíduo na sociedade contemporânea.

Esse conjunto de habilidades, conhecido como Competência em Informação, assim como o próprio conceito de informação, foi se ajustando às demandas da sociedade e da academia, enfatizando por um dado momento os aspectos físicos da informação, em um segundo momento, os aspectos cognitivos, e em um terceiro, os aspectos sociais que cercam a produção, a organização e a disseminação da informação.

A presente pesquisa não teve como pretensão a exaustividade, oferecendo provas contundentes de que a Competência em Informação tenha passado por três fases diferentes comparadas aos paradigmas da informação de Rafael Capurro (2003), mas dar início a possíveis discussões sobre a história da temática, assim como sobre as interações conceituais, teóricas e metodológicas entre a Teoria da Informação e a Competência em Informação. 


\section{Referências}

AMERICAN ASSOCIATION OF SCHOOL LIBRARIANS. Standards for the 21stCentury in Action. Chicago, IL: AASL, 2009.

AMERICAN LIBRARY ASSOCIATION. Presidential commitee on information literacy: final report. Washington, DC: ALA, 1989.

ARAÚJO, Carlos Alberto Ávila de. Fundamentos da Ciência da Informação: correntes teóricas e o conceito de informação. Perspectivas em Gestão \& Conhecimento, João Pessoa, v. 4, n. 1, p. 57-79, jan./jun. 2014. Disponível em:

http://periodicos.ufpb.br/ojs/index.php/pgc/article/view/19120. Acesso em: 28 jun. 2018.

ARAÚJO, Carlos Alberto Ávila de. O conceito de informação na Ciência da Informação.

Informação \& Sociedade: estudos, João Pessoa, v. 20, n. 3, p. 95-105, set./dez. 2010.

Disponível em:

https://www.researchgate.net/publication/277240372_O_conceito_de_informacao_na_Cienci a_da_Informacao. Acesso em: 18 dez. 2019.

BEHRENS, Shirley J. A conceptual analysis and historical overview of information literacy. College \& Research Libraries, v. 55, n. 4, p. 309-322, jul. 1994. Disponível em: https://crl.acrl.org/index.php/crl/article/view/14902/16348. Acesso em: 28 jun. 2018.

BORGES, Jussara. A contribuição das pesquisas em competências infocomunicacionais ao conceito de Media and Information Literacy. Revista Brasileira de Biblioteconomia e Documentação, São Paulo, v. 13, n. esp., p. 27-46, jan./jul. 2017. Disponível em: < https://rbbd.febab.org.br/rbbd/article/view/667/569>. Acesso em 28 jun. 2018.

BORKO, Harold. Information Science: what is it? American Documentation, [s. l.], p. 3-5, jan. 1968. Disponível em:

https://www.marilia.unesp.br/Home/Instituicao/Docentes/EdbertoFerneda/k---artigo-01.pdf. Acesso em: 28 jun. 2018.

BROOKES, Bertam C. The foundations of information science: part i. philosophical aspects. Journal of Information Science, [s. l.], v. 2, p. 125-133, 1980.

CAMPELLO, Bernadete. O movimento da competência informacional: uma perspectiva para o letramento informacional. Ciência da Informação, Brasília, v. 32, n. 3, p. 28-37, set./dez. 2003. Disponível em: http://www.scielo.br/pdf/ci/v32n3/19021.pdf. Acesso em: 24 maio 2019.

CAPURRO, Rafael. Epistemologia e Ciência da Informação. In: ENCONTRO NACIONAL DE PESQUISA EM CIÊNCIA DA INFORMAÇÃO, 5., 2003. [Anais...]. Belo Horizonte: ANCIB, 2003. Disponível em: http://www.capurro.de/enancib_p.htm. Acesso em: $18 \mathrm{dez}$. 2019.

CAPURRO, Rafael; HJORLAND, Birger. O conceito de informação. Perspectivas em Ciência da Informação, Belo Horizonte, v. 12, n. 1, p. 148-207, jan./abr. 2007. Disponível em: https://www.scielo.br/pdf/pci/v12n1/11.pdf. Acesso em: 28 jun. 2018. 
CRESPO, Isabel Merlo; CAREGNATO, Sônia Elisa. Comportamento de busca de informação: uma comparação de dois modelos. Em questão, Porto Alegre, v. 9, n. 2, p.271281, jul./dez. 2003. Disponível em: https://seer.ufrgs.br/EmQuestao/article/view/73/33. Acesso em: 18 dez. 2019.

DOYLE, Andréa. Ideologia e competência crítica em informação: um olhar para movimentos de Biblioteconomia crítica. Folha de Rosto, Juazeiro do Norte, v. 4, n. 1, p. 25-33, jan./jun. 2018. Disponível em:

https://periodicos.ufca.edu.br/ojs/index.php/folhaderosto/article/view/274. Acesso em: $18 \mathrm{dez}$. 2019.

DUDZIAK, Elisabeth Adriana Dudziak. Information literacy: princípios, filosofia e prática. Ciência da Informação, Brasília, v. 32, n. 1, p. 23-35, jan./abr. 2003. Disponível em: http://revista.ibict.br/ciinf/article/view/1016/1071. Acesso em: 18 dez. 2019.

FARÓIS da sociedade da informação: declaração de Alexandria sobre competência em informação e aprendizado ao longo da vida. Alexandria: IFLA, 2005.

FRAMEWORK for information literacy for higher education. [s. l.]: ACRL, 2016. Disponível em:

http://www.ala.org/acrl/sites/ala.org.acrl/files/content/issues/infolit/Framework_ILHE.pdf. Acesso em: 28 jun. 2018.

HJØRLAND, Birger. Theoretical development of information science: a brief history. Journal of Information Science, [s. l.], v. 1, p. 1-17, 2014.

MARCO de avaliação global da alfabetização midiática e informacional: disposição e competências do país. Brasília: UNESCO, 2016. Disponível em:

https://unesdoc.unesco.org/ark:/48223/pf0000246398. Acesso em: 18 dez. 2019.

OWENS, R. The state government \& libraries. Library Journal, [s. l.], v. 101, n. 1, p. 19-28, jan. 1976.

QUEIROZ, Daniela Gralha de Caneda; MOURA, Ana Maria Mielniczuk de. Ciência da Informação: história, conceitos e características. Em Questão, Porto Alegre, v. 21, n. 3, p. 3542, ago./dez. 2015. Disponível em: https://dialnet.unirioja.es/descarga/articulo/6142013.pdf. Acesso em: 18 dez. 2019.

SARACEVIC, Tefko. Ciência da informação: origem, evolução e relações. Perspectivas em Ciência da Informação, Belo Horizonte, v. 1, n. 1, p. 41-62, jan./jul. 1996. Disponível em: http://portaldeperiodicos.eci.ufmg.br/index.php/pci/article/view/235/22. Acesso em 28 jun. 2018.

SILVA, Armando Malheiro da. Mediações e mediadores em Ciência da Informação. Prisma, [s. l.], n. 9, p. 68-104, 2009. Disponível em: http://www.brapci.inf.br/index.php/res/download/86496. Acesso em 18 dez. 2019.

VITORINO, Elizete Vieira; PIANTOLA, Daniela. Competência informacional: bases históricas e conceituais: construindo significados. Ciência da Informação, Brasília, v. 38, n. 3, p. 130-141, set./dez. 2009. Disponível em: http://www.scielo.br/pdf/ci/v38n3/v38n3a09.pdf. Acesso em 24 maio 2019. 
VITORINO, Elizete Vieira; PIANTOLA, Daniela. Dimensões da competência informacional (2). Ciência da Informação, Brasília, v. 40, n. 1, p. 99-110, jan./abr. 2011. Disponível em: http://www.scielo.br/pdf/ci/v40n1/a08v40n1.pdf. Acesso em 24 maio 2019.

ZURKOWSKI, Paul. The information servisse environment relationships and priorities. Washington: NCLIS, 1974. Disponível em: https://files.eric.ed.gov/fulltext/ED100391.pdf. Acesso em 28 jun. 2018. 